\title{
Comparative Screening of Phytochemical Compounds in Scent Leaf (Ocimumgratissimum) and Bitter Leaf (Vernonia amygdalina) Extracts
}

\author{
RN Oladosu-Ajayi ${ }^{1 *}$, HE Dienye ${ }^{2}$, CT Ajayi ${ }^{1}$, OD Erinle ${ }^{1}$ \\ ${ }^{1}$ Department of Fisheries Technology, FCFFT, New Bussa, Niger State, Nigeria \\ ${ }^{2}$ Department of Fisheries, University of Port Harcourt, Rivers State, Nigeria
}

"Corresponding author: Oladosu-Ajayi RN, Department of Fisheries Technology, FCFFT, New Bussa, Niger State, Nigeria. Email: oladosuajayi@gmail.com

Citation: Oladosu-Ajayi RN, Dienye HE, Ajayi CT, Erinle OD (2017) Comparative Screening of Phytochemical Compounds in Scent Leaf (Ocimumgratissimum) and Bitter Leaf (Vernonia amygdalina) Extracts. J Fish Aquac Dev: JFAD-112. DOI:10.29011/ JFAD-112/100012

Received Date: : 17 June, 2017; Accepted Date: 15 July, 2017; Published Date: 22 July, 2017

\begin{abstract}
Phytochemical screening of the leaves of Ocimum gratissimum and Vernonia amygdalina revealed the presence of alkaloids, flavonoids, steroid, tannins, and caroternoid. The best solvent of extraction for both plants was the hot water followed by the cold water even though they were unable to liberate flavonoids from bitter leaf extracts. The washed bitter leaf extracts contained more alkaloids than the extracts made from the unwashed leaf though the differences were not significant (washed bitter leaf-7.32\% from hot water and $6.83 \%$ from cold water, unwashed bitter leaf- $6.12 \%$ from hot water and $5.32 \%$ from cold water). The ethanolic extracts of bitter leaf liberated the flavonoids while the hot water was also able to liberate it from the scent leaf. Carotenoids were liberated from the extracts of both plants though the quantities were not significantly different.The study showed that bitter leaf and scent leaf contain similar antimicrobial compounds but former contains more quantity.
\end{abstract}

Keywords: Bitter Leaf; Phytochemical; Scent Leave

\section{Introduction}

Phytochemical screening is a process of tracing the medicinal value of plants constituents in some chemical substance that produce a definite physiologic action on the human body [1,2]. The most important of these bioactive compounds of plants are alkaloids, flavonoids, tannins, saponins, glycosides,cardenolides, bufadionolides and polyphenolic compounds [3]. Knowledge of the chemical constituents of plants is desirable not only for the discovery of therapeutic agents but also because such information may be of value in disclosing new sources of such economic materials as tannins, oils, gum, precursors for the synthesis of complex chemical substances [3]. Bitter leaf (Vernonia amygdalina) is derived from the leaves of a small ever-green shrub found all over Africa belonging to the family Asteraceace. It is well known as a medicinal plant for diabetes and fever [4].Vernonia amygdalina (Del.) commonly called bitter leaf is the most widely cultivated species of the genus Vernonia which has about 1,000 species of shrubs [5]. It belongs to the family Astaraceae. It is vegetatively cultivated by stem cutting at an angle of $45^{\circ}$ and popular in most of West Africa countries including Nigeria, Cameroon, Gabon and Congo Democratic Republic. Although most popularly used for food, it has also, been traditionally used for its medicinal proper- ties. True to its name, bitter leaf is bitter to taste but surprisingly delicious in meals. Bitter leaf is called Omjunso in East Africa especially Tanzania, Onugbo in Igbo-Eastern Nigeria and Orugbo among the Itsekiri and Urhobo tribes in Nigeria, Ewuro (Yoruba), Etidot (Ibibio), Ityuna (Tiv), Oriwo (Edo), Chusa-doki Shiwaka (Hausa). Scent leaf, Ocimum gratissimum is an aromatic perennial herb, with erect stem, much branched, glabrous and woody at the base often with epidermic peeling in strips.Ocimum gratissimum is grown for the essential oil in its leaves and stems whileengenol and to a lesser extent thymol extracted from the oil are substitutes from clove oil and thyme oil.The essential oil possesses antibacterial properties and is also an important insect repellent so also are the leaves when left dry and burnt [6]. They are primarily used as vegetables [7], as spice due to its aromatic nature to spice various kinds of soup (e.g. pepper soup) and other delicious meals like porridge [6]. The whole plant has many applications in traditional medicine especially in Africa and India.The applications include in the treatment of ringworms, gout and fungal infections, malaria, catarrh, aches, colon pain. The juice gotten from squeezing its leaf can be used to cure several stomach related illnesses like cholera, diarrhea, dysentery, vomiting and convulsion [6]. Ocimum gratissimum and Vernonia amygdalina plants are known to have common phytochemical compounds which are non-nutritive plants and significant used in traditional medicine for the treatment of sev- 


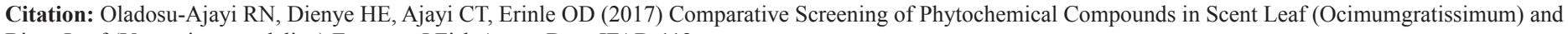
Bitter Leaf (Vernonia amygdalina) Extracts. J Fish Aquac Dev: JFAD-112.

eral ailments and the extracts have been evaluated for their ability to stall the activities of organisms responsible for spoilage of fresh catfish (Clariasgariepinus) thereby extending its shelflife [8]. Therefore, the study aims to know the quantity of the phytochemical compounds present in the extracts of scent leaf (Ocimum gratissimum) and bitter leaf (Vernonia amygdalina) and also to know which solvent of extraction contains more of the phytochemical compounds.

\section{Materials and Methods}

\section{Collection of Plant Materials}

Fresh leaves of Ocimum gratissimum and Vernonia amuglidana were collected from a home garden inside the National Institute of Freshwater Fisheries Research (NIFFR) residential quarters in Kainji, New-Bussa, Niger state.

\section{Preparation of Bitter and Scent Leaf Extracts}

The bitter leaf (Vernonia amygdalina) and scent leaf (Ocimum gratissimum) were washed with clean water to remove the dust and dirts. This was macerated and divided into two portions, one part of the bitter leaf was unwashed and the other part was washed to remove part of the juice that is responsible for the bitter taste. The extraction was done as follows according to[9].

- $\quad 300 \mathrm{~g}$ of bitter leaf was soaked in $150 \mathrm{ml}$ of $95 \%$ ethanol for 24hours. The pulp obtained was left in clean, sterile glass container and shaken vigorously to allow for proper extraction. Filtration was done using a sterile muslin cloth after which the extract obtained was air-dried and store for use.

- $300 \mathrm{~g}$ of bitter leaf was soaked in $150 \mathrm{ml}$ of cold water for 24hours and the resultant juice extracted was air dried and stored as done in (1) above.

- $\quad 300 \mathrm{~g}$ of bitter leaf was soaked in $150 \mathrm{ml}$ of hot water for 24hours and the resultant juice extracted was air dried and stored as done in (1) above.

The scent leaf extracts were also prepared using the above procedure.

\section{Qualitative Analysis of Phytochemical Compounds}

Qualitative analysis was carried out to ascertain the presence of the different phytochemical compounds in the leaves. The method used and their corresponding inferences are shown below (Appendix)

\begin{tabular}{|c|c|c|c|c|}
\hline & Phytochemical & Test & Observation & Inference \\
\hline 1 & Alkaloid & Wagner dragendroffs & $\begin{array}{c}\text { Brown precipitate which turns intense yellow } \\
\text { with the picnic acid }\end{array}$ & Alkaloid present \\
\hline 2 & Tannins & Ferric chloride & Greenish - blackprecipitate & Tannin present \\
\hline 3 & Flavonoid & $\begin{array}{c}\text { Ammonium andsodium hydroxide } \\
\text { acid }\end{array}$ & $\begin{array}{c}\text { Yellow colour which turns colourless on addi- } \\
\text { tion of acid }\end{array}$ & Flavonoid present \\
\hline 4 & Steroids & Liberman Burchard and Salkowkis & Brownish colour Red colour at interference & Steroid present \\
\hline
\end{tabular}

Appendix: Qualitative Analysis of Phytochemical Compounds Method Used and Their Corresponding Inferences [10].

\section{Quantitative Analysis of Phytochemical Compounds}

Determination of Alkaloids: This was done by the alkaline precipitation gravimetric method described by Harborne [10]. A measured weight of the sample was dispersed in 95\% acetic acid solution in ethanol to form a ratio of 1:95(95\%). The mixture was allowed to stand for 24 hours. The filtrate was concentrated to one quarter of its original volume by evaporation and treated with drop wise addition of concentrated aqueous $\mathrm{NH}_{4} \mathrm{OH}$ until the alkaloid was precipitated. The alkaloid precipitated was received in weighed filter paper, washed with $1 \%$ ammonia solution dried in the oven at $80^{\circ} \mathrm{C}$. Alkaloid content was calculated and expressed as a percentage of the weight of sample analysed.

Determination of Flavonoids: This was determined according to the method of Harborne [10]. 300gram of the same was boiled in $150 \mathrm{ml}$ of $2 \mathrm{M} \mathrm{HCL}$ solution for $30 \mathrm{mins}$ under reflux. It was allowed to cool and then filtered through Whatman No 42 filter paper. A measured volume of the extract was treated with equal volume of ethyl acetate starting with a drop.The flavonoids precipitated were recovered by filtration using weighed filter paper. The resulting weight difference gave the weight of flavonoids in the sample.

Determination of Carotenoids: A measured weight of each sample was homogenized in ethanol using a laboratory blender. A 1:10 (1\%) mixture was used. The homogenate was filtered to obtain the initial crude extracts. $20 \mathrm{ml}$ of ether were added to the filtrate to take up the carotenoids mixed well and then treated with $20 \mathrm{ml}$ of distilled water in a separating funnel. The other layer was recovered and evaporated to dryness at low temperature $\left(35-50^{\circ} \mathrm{C}\right)$ in a vacuum dessicator. The dry extract was then saponified with $20 \mathrm{ml}$ of ethanolic potassium hydroxide and left over night in a dark cupboard. The next day, the carotenoid was taken up in $20 \mathrm{ml}$ of ether and then washed with two portions of $20 \mathrm{ml}$ - distilled water. The carotenoid extract (ether layer) was dried in a dessicator and then treated with a light petroleum (petroleum spirit) and allowed to stand overnight in a freezer $\left(-10^{\circ} \mathrm{C}\right)$. The next day the precipitation steroid was removed by centrifugation and the carotenoid extracts was evaporated to dryness in a weighed evaporation dish, cooled in a desiccator and weighed. The weight of carotenoid was determined was expressed as a percentage of the sampleweight[11]. 


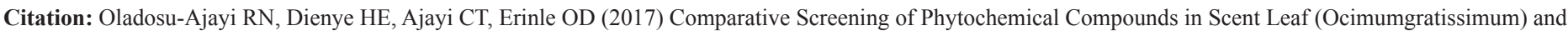
Bitter Leaf (Vernonia amygdalina) Extracts. J Fish Aquac Dev: JFAD-112.

\section{Results}

Table-1 shows the phytochemical compounds present in the extracts of washed bitter leaf. Flavonoids were absent in the hot water extracts while alkaloids, tannins and steroids are present. Also flavonoids and tannins were absent in the cold water extract while steroids and alkaloids were present. Tannins were not present in the ethanolic extract while the alkaloids, steroids and flavonoids were present.Table-2 shows the screening of unwashed bitter leaf extract. Flavonoids and steroids were absent in the hot water extract while it was only the flavonoids that were absent in the cold water extract. The ethanol extract was able to liberate flavonoids, alkaloids and tannins with the exception of the steroids. Table- 3 shows the phytochemical compounds present in the extract of washed scent leaf. Steroids and tannins were absent in the ethanolic extract while tannins were absent in the hot water extract. The cold-water extract was able to liberate the alkaloids and steroids. Table-4 shows the phytochemical compounds present in the extract of unwashed scent leaf. Steroids were absent in the hot water extract while only alkaloids were present in the cold water extract. The ethanolic extract showed the presence of alkaloids and tannins.Table-5 summarizes the result of quantitative screening of phytochemicals present in washed bitter leaf extracts. Alkaloid has the highest quantity $17.08 \%$ which present in ethanolic. Cold and hot water extract, also flavonoids as $2.32 \%$ present in ethanolic extract only while carotenoids has $0.135 \%$ in ethanolic, cold and hot water extracts. Table- 6 summarizes the quantity of phytochemicals found in unwashed bitter leaf extracts. Alkaloids has the highest amount $14.56 \%$ in ethanolic, hot and cold-water extract and flavonoids has $2.42 \%$ in ethanolic, cold and hot water extracts only followed by carotenoid which has $0.24 \%$ in ethanolic, cold and hot water extracts. Table-7 shows the quantity of phytochemical compounds in washed scent leaf extracts. Alkaloids has $5.86 \%$ in ethanolic, cold and hot water extract which flavonoids has $3.28 \%$ in ethanolic, and hot water and not found in cold water extract and carotenoids has $0.2 \%$ in ethanolic hot and cold-water extracts. Table- 8 shows the quantity of phytochemical compounds in the extracts of unwashed scent leaf. Alkaloids has $7.82 \%$ in ethanolic, cold and hot water extracts and flavonoids $2.11 \%$ in hot water extract and not found in ethanolic and cold-water extracts while carotenoids have $0.22 \%$ in both ethanol, hot and cold-water extracts.

\begin{tabular}{|c|c|c|c|c|}
\hline & Alkaloids & Flavonoids & Steroids & Tannin \\
\hline HWE & + & - & + & + \\
\hline CWE & + & - & + & - \\
\hline EE & + & + & + & - \\
\hline
\end{tabular}

Table 1: Qualitative screening of washed bitter leaf extracts.

\begin{tabular}{|c|c|c|c|c|}
\hline & Alkaloids & Flavonoids & Steroids & Tannin \\
\hline HWE & + & - & - & + \\
\hline CWE & + & - & + & + \\
\hline EE & + & + & - & + \\
\hline
\end{tabular}

Table 2: Qualitative screening of unwashed bitter leaf extracts.

\begin{tabular}{|c|c|c|c|c|}
\hline & Alkaloids & Flavonoids & Steroids & Tannin \\
\hline EE & + & + & - & - \\
\hline HWE & + & + & + & - \\
\hline CWE & + & - & + & - \\
\hline
\end{tabular}

Table 3: Qualitative screening of washed scent leaf extracts.

\begin{tabular}{|c|c|c|c|c|}
\hline & Alkaloids & Flavonoids & Steroids & Tannin \\
\hline HWE & + & + & - & + \\
\hline CWE & + & - & - & - \\
\hline EE & + & - & - & + \\
\hline
\end{tabular}

Table 4: Qualitative screening of unwashed scent leaf extracts.

\begin{tabular}{|c|c|c|c|}
\hline & Alkaloids & Flavonoids & Carotenoids \\
\hline EE & 2.93 & 2.32 & 0.045 \\
\hline CWE & 6.83 & -- & 0.04 \\
\hline HWE & 7.32 & -- & 0.05 \\
\hline
\end{tabular}

Table 5: Quantitative screening of washed bitter leaf extract in $\%(\mathrm{~g} / 100 \mathrm{~g})$.

\begin{tabular}{|c|c|c|c|}
\hline & Alkaloids & Flavonoids & Carotenoids \\
\hline EE & 3.12 & 2.42 & 0.14 \\
\hline CWE & 5.32 & -- & 0.06 \\
\hline HWE & 6.12 & -- & 0.07 \\
\hline
\end{tabular}

Table 6: Quantitative screening of unwashed bitter leaf extract $\%(\mathrm{~g} / 100 \mathrm{~g})$.

\begin{tabular}{|c|c|c|c|}
\hline & Alkaloids & Flavonoids & Carotenoids \\
\hline EE & 2.56 & 1.88 & 0.10 \\
\hline CWE & 1.88 & -- & 0.04 \\
\hline HWE & 1.40 & 1.40 & 0.06 \\
\hline
\end{tabular}

Table 7: Quantitative screening of washed Scent leaf extract in $\%(\mathrm{~g} / 100 \mathrm{~g})$.

\begin{tabular}{|c|c|c|c|}
\hline & Alkaloids & Flavonoids & Carotenoids \\
\hline EE & 1.75 & -- & 0.11 \\
\hline CWE & $1 . .43$ & -- & 0.03 \\
\hline HWE & 4.64 & 2.11 & 0.08 \\
\hline
\end{tabular}

Table 8: Quantitative screening of unwashed Scent leaf extract in $\%(\mathrm{~g} / 100 \mathrm{~g})$. 
Citation: Oladosu-Ajayi RN, Dienye HE, Ajayi CT, Erinle OD (2017) Comparative Screening of Phytochemical Compounds in Scent Leaf (Ocimumgratissimum) and Bitter Leaf (Vernonia amygdalina) Extracts. J Fish Aquac Dev: JFAD-112.

\section{KEY}

$\mathbf{E E}=$ Ethanolic Extract

HWE $=$ Hot Water Extract

$\mathbf{C W E}=$ Cold Water Extract

SUN $=$ Scent Leaf Unwashed

$$
\begin{aligned}
& \text { BW = Bitter Leaf Washed } \\
& \text { BUN = Bitter Leaf Unwashed } \\
& \text { SW }=\text { Scent Leaf Washed } \\
& +=\text { Present }-=\text { Absent }
\end{aligned}
$$

\section{Discussion}

The results obtained from this study showed that hot water, cold water and ethanolic extracts of the plants have varying contents of the phytochemical compounds. It also shows that even though the two plants contain similar phytochemical compounds, the quantities differ. The aqueous extracts of the bitter leaf contained the highest quantities of alkaloids (Tables 5 and 6). This was obvious in the washed and unwashed bitter leaf (washed: Cold water extract- $6.83 \%$ and Hot water extract-7.32\%; unwashed: Cold water extract-5.32\% and Hot water extract-6.12\%). Therefore, it can be concluded that alkaloids are more revealed in bitter leaf extract when it is washed, although an appreciable quantity can also be gotten when it is not washed. It can also be deduced from this experiment that alkaloids are not heat labile since the highest quantity was liberated from the hot water extract. The ethanolic extracts contained the least quantities (washed: $2.93 \%$ and unwashed: $3.12 \%$ ). This means that as much as ethanol is an organic solvent and is an excellent phytochemical compound liberator, it was unable to exhibit those characteristics in the extraction of alkaloids from bitter leaf extracts. This isunlike the findings of Epraim[12] who got more alkaloids from the ethanolic extracts of black pepper seeds and pawpaw seeds. The study also discovered that the hot water extracts of the two plants (black pepper and pawpaw seeds) liberated more alkaloids than the coldwater extracts. The carotenoids were also not well liberated by the aqueous extracts (cold and hot water). Bitter leaf (washed and unwashed) extracts contained very low content of flavonoidscompared to the alkaloids. Hot water extract retained more of the vitamin compared to cold water extracts. Carotenoid levels increased in hot water extracts $0.05 \mathrm{~g} / 100 \mathrm{~g}$ while the content was reduced in cold water extracts $0.04 \mathrm{~g} / 100 \mathrm{~g}$. The resistance of carotenoid to the effect of heat is in line with the earlier report of Anderson (2002) that phytochemical compounds are not affected by processing. It can thus be said about bitter leaf that the phytochemical compounds are better liberated after washing using either the hot or cold water as solvents of extraction while the flavonoids content can only be revealed in the ethanolic extract.

Scent leaf contains the same phytochemical compounds as the bitter leaf but it was revealed from the results of this study that more of these compounds can be found in the latter. Unlike the bitter leaf, the aqueous extracts did not liberate much alkaloids (washed: Cold water extract-1.88\% and Hot water extract-1.40\%; unwashed: Cold water extract-1.43\% and Hot water extract-4.64\%) while the ethanolic extract liberated $2.56 \%$. This means that to use hot water as solvent of extraction for flavonoids, the scent leaf should not be washed while it should be washed and ethanol used as solvent of extraction when alkaloids are being screened for. Erinle (2012) reported that the pigment taste of scent leaf is contributed by its high content of alkaloid. The hot water extract of the unwashed scent leaf can also be depended upon for flavonoids even though the ethanolic extract of the washed sample can also be screened for it. This result thus infers that flavonoids in the scent leaf are not well liberated and are not heat labile.

Generally, heating did not significantly affect the carotenoid content of the leaf. This indicates that carotenoid (colored pigment) remained stable during heating, though there was slight reduction in carotenoids content in ethanolic extracts and hot water extracts.

\section{Conclusion}

The results from this work has shown that the ethanolic, hot and cold water extracts of the plants under study contains many phytochemical compounds which include alkaloids, steroids, flavonoids, carotenoids and tannins which are responsible for their various activities and also may account for medicinal benefits. It can be concluded from this work that the different solvents of extraction have varying abilities to liberate these compounds and the quantities that each liberate has been ascertained.The selected plants contain substantial amount of phytochemical which are helpful in the prevention of some deadly diseases. Scent leaf, (Ocimum gratissimum)and bitter leaf (Vernonia amygdalina) leaves could help fulfill the growing demands of plant based foods for human nutrition.

\section{References}

1. Jigna P, Nehel K, Sumitra C (2006) Evaluation of Antibacterial and Phytochemical Analysis of Bauhiniavariegate L. bark. Afri J Biomed Res 9: 53-56.

2. Allero AA, Afolayan AJ (2006) Antimicrobial Activity of Solanum tomentosum. AfriJ Biotechnol 5: 369-372.

3. Erinle OD (2012) Phytochemical Screening of Scent leaf (Ocimum gratissimum) and bitter leaf (Vernoniaamygdalina) extracts. ND Project, FCFFT, New Bussa, Niger State 1-5.

4. Adenuga W, Olaleye ON, Adepoju PA (2010) Utilization of bitter vegetable leaves (Gongronemalatifolium, Vernonia amygdalina) and Garcinia kola extracts as substitutes for hops in sorghum beer production. Afri J Biotechnol9: 8819-8823.

5. Muanya C (2015) Scent and Bitter Leaves Retard Growth of Cancers, Boost Immune System. Guardian Newspaper Publication of 3rd September.

6. Health Facts NG (2015) Health Facts. Designed by iQube Labs. 
Citation: Oladosu-Ajayi RN, Dienye HE, Ajayi CT, Erinle OD (2017) Comparative Screening of Phytochemical Compounds in Scent Leaf (Ocimumgratissimum) and Bitter Leaf (Vernonia amygdalina) Extracts. J Fish Aquac Dev: JFAD-112.

7. Sulistiarini D (1999) Ocimum gratissimum. Oyen LM, Nguyen LPA, Xuan, Duan (Eds): Plant Resources of South East Asia. No 19: Essential-oils plants. Prosea foundation bojor, Indonesia 140-142.

8. Oladosu-Ajayi RN, Dienye HE, Ajayi CT, Agha IU (2016) Vernonia amygdalina [Bitter leaf] extracts as preservative for catfish, Clariasgariepinus. International Journal of Nutritional Science and Food Technology 3: 2471-7371.

9. Azu, Nelson C, Onyeagba, Reginald A (2007) Antimicrobial Properties of Extracts of Allium cepa (onions) and Zingier officinale (ginger) on Escherichia coli, Salmonella typhi and Bacillus subtilis. The Internet Journal of Tropical Medicine 3: 1.
10. Harborne JB (1973) Phytochemical Methods. London, Chapman and Hall. Ltd 49-188.

11. Okafor JC (1987) Identification and Conservation of plants Used in Traditional Medicine. Paper presented at the International Workshop on Evaluation of traditional Medicines. University of Nigeria, Nsukka, Nigeria: 62-68.

12. Ephraim RN (2010) Antimicrobial Properties of extracts Carica papaya and Piper guineese on Microorganisms Associated with Catfish, Clariasgariepinus spoilage. M.Sc. Dissertation; University of Agriculture, Abeokuta (UNAAB) Ogun State, Nigeria 87. 